\title{
Inter-observer agreement of paranasal sinus computed tomography scans
}

\author{
Julkunen, Anna
}

2017-06

Julkunen , A , Terna , E , Numminen , J , Markkola , A , Dastidar , P , Karjalainen , M ,

Huhtala , H , Rautiainen, M , Meurman , J \& Toppila-Salmi , S 2017 , ' Inter-observer

agreement of paranasal sinus computed tomography scans ' , Acta Oto-Laryngologica, vol.

137 , no. 6 , pp. 611-617 . https://doi.org/10.1080/00016489.2016.1262552

http://hdl.handle.net/10138/310611

https://doi.org/10.1080/00016489.2016.1262552

unspecified

acceptedVersion

Downloaded from Helda, University of Helsinki institutional repository.

This is an electronic reprint of the original article.

This reprint may differ from the original in pagination and typographic detail.

Please cite the original version. 


\section{Inter-observer agreement of paranasal sinus computed tomography scans}

BDent Julkunen Anna ${ }^{1,7}$, BDent Terna Emma ${ }^{1}$, MD PhD Numminen Jura ${ }^{2,3}$, MD PhD Markkola Antti $^{4}$, MD PhD Dastidar Prasun ${ }^{5}$, MD Karjalainen Matti ${ }^{2}$, MSci Huhtala Heini ${ }^{6}$, MD Prof Rautiainen Markus ${ }^{2,3}$, MD Prof Meurman Jukka ${ }^{7}$, MD PhD Toppila-Salmi Sanna ${ }^{1,8}$

${ }^{1}$ Transplantation laboratory, Haartman Institute, University of Helsinki, Helsinki, Finland

${ }^{2}$ Department of Otorhinolaryngology, University of Tampere, Tampere, Finland

${ }^{3}$ Department of Ear and Oral diseases, Tampere University Hospital, Tampere, Finland

${ }^{4}$ University of Helsinki and HUS Imaging, Helsinki, Finland

${ }^{5}$ Medical Imaging Centre, Department of Radiology, Tampere University Hospital, Finland

${ }^{6}$ School of Public Health, University of Tampere, Tampere, Finland

${ }^{7}$ Department of Oral and Maxillofacial Diseases, University of Helsinki and Helsinki University Hospital, Helsinki, Finland

${ }^{8}$ Department of Allergy, University of Helsinki and Helsinki University Hospital, Helsinki, Finland

Address correspondence and reprint requests to Anna Julkunen

anna.julkunen@helsinki.fi

Address: Haartman Institute, PO BOX 21 (Haartmaninkatu 3), 00014 University of Helsinki, Helsinki, Finland

Phone number: $+358-456783186$

Running title: Inter-observer agreement of sinus CT

Key Words CT, inter-observer, reproducibility, chronic rhinosinusitis, sinus imaging 


\section{Abstract}

Conclusion: The study demonstrated considerable inter-observer variation in certain surgically important structures. This would indicate the significance for consultation when evaluating sinus CT scans of CRS patients for planned advanced sinus surgery.

Objectives: After the failure of medical treatment of chronic rhinosinusitis (CRS), the need for surgery and the preoperative planning of safe surgery is based on computed tomography (CT) findings. The aim of this prospective study was to compare inter-observer agreement of anatomical and surgical structures of sinus CT scans. The hypothesis was that the agreement between observers is good.

Methods: Of these 57 CRS patients, Lund-Mackay (LM) scores and 43 other structural parameters were analyzed blinded. The reproducibility of the findings between three observers, a radiologist, an Ear, nose and throat (ENT) surgeon, and an ENT resident, were compared.

Results: In general, there was moderate inter-observer agreement of the structures by Cohen's kappa coefficient. Poor reproducibility was observed in the following structures: optic nerve, insertion of the uncinated process, anterior ethmoidal artery, and Keros class.

\section{Key Words}

CT, inter-observer, reproducibility, chronic rhinosinusitis, sinus imaging

\section{Abbreviations}

$\mathrm{CT}=$ Computed tomography, $\mathrm{CRS}=$ Chronic rhinosinusitis, $\mathrm{ENT}=$ ear nose throat

\section{Introduction}


Chronic rhinosinusitis (CRS) is a common, multifactorial and variable disease with a prevalence of around $10-16 \%$ [1]. The diagnostics of CRS is based on typical symptoms and clinical findings [1]. After the failure of medical treatment, the severity of CRS and the putative need for surgery is assessed based on the history, endoscopy, other clinical findings and imaging [1].

Computed tomography (CT) scans are the imaging modality of choice confirming the extent of pathology and the need for surgery. It is important to verify CRS with the CT scans because the symptom of the patient does not always correlate with disease [2]. The main findings in CRS are mucosal changes within the osteomeatal complex and/or sinuses. Other characteristic findings of CRS are air-fluid levels, mucosal thickening and opacification of the normally aerated sinus lumen. The only change can be sclerotic, thickened bone of the sinus wall [1]. A number of CT-staging systems of CRS exist; the Lund-Mackay staging is one of the most used. Staging is based on degree of opacification $(0=$ normal, $1=$ partial opacification, $2=$ total opacification $)$ of each sinus: maxillary, anterior ethmoid, posterior ethmoid, sphenoid and frontal sinus, for each side. In addition, the ostiomeatal complex $(\mathrm{OMC})$ is graded as $0=$ not occluded, or $2=$ occluded; coming to a maximum score of 12 per side $[3,4]$.

Sinus CT scans are an integral part of preoperative planning. The important structures in planning sinus surgery are insertion of middle turbinate and the uncinated process, the location of anterior ethmoidal artery, and Keros class, Infraorbital cells, position of the Agger nasi cell, and the anatomical variants located in the operative area [5-10].

A few previous studies have evaluated inter-observer reproducibility of CT scans. It has been shown that there can be variability between inter-observer agreements in computed tomography images. 
Particularly there have been major differences between an experienced observer and an inexperienced observer $[8,11]$. However, a study of shoulder CT scans showed that there can also be differences between equally experienced observers [12].

To the best of knowledge of the authors there is limited information of the inter-observer reliability of sinus CT scans. The number of anatomical variants is very high in paranasal sinuses $[13,14]$. Several of them (such as big vessels, orbit and CNS) are located close to sinonasal surgical area and thus the intraoperative lesions of them may lead to severe illness or be life threating. This crosssectional study aimed at evaluating the inter-observer agreement of 49 structures of sinus CT scans. The objective was to compare the results between doctors with different expertise and experience. We hypothesized that the inter-observer agreement is good.

\section{Materials and Methods}

This study was carried out in the Department of Otorhinolaryngology, at Tampere University Hospital, Finland from 2006 to 2009. The study was approved by the ethical committee of the Pirkanmaa Hospital District (no 96032). Written informed consent was obtained of each participant. A random sample of 57 patients suffering from CRS, who were evaluated to benefit from sinus CT scans during 2006-2007 at the Tampere University Hospital, were enrolled to this study.

\section{CT scans}

The patients underwent routine sinus multiple detector computed tomography (MDCT) examinations for clinical purposes. Two different MDCT machines were used: GE LightSpeed 16 (GE Healthcare, Milwaukee, Wisconsin) and Philips Brilliance 64 (Philips, Best, Netherlands). The patients were imaged in supine position with a kilovoltage of $120 \mathrm{kV}$ and a milliampere second of $100 \mathrm{mAs}$. In the GE machine, the slice thickness was $0.625 \mathrm{~mm}$ with coronal reconstructions at $1.5 \mathrm{~mm}$. In the Philips 
machine, the slice thickness was $0.9 \mathrm{~mm}$ with coronal reconstructions at $0.9 \mathrm{~mm}$. Both were three dimensional (3D) in nature without any gap. In all cases, the imaging was performed using a bone filter technique. The imaging covered the entire sinonasal area both in the axial and coronal directions. The coronal reformations spanned through the entire area, starting from the anterior wall of the frontal sinuses and ending to the level of the posterior wall of the sphenoid sinuses.

\section{Evaluation of CT scans}

CT scans were observed by three independent observers blinded to each other and to the patient history data. The focus was to compare agreement between there observers in evaluating radiological anatomy sinonasal structures and CRS-related changes. The observers were an experienced head and neck radiologist (AM), an experienced ENT- and rhinosurgeon $(\mathrm{JN})$, and a fifth year ENT resident (ST-S). They filled in a 49 -item form of sinonasal structures from both sides (Table 3). All asked structures had 2-5 different choices. Before starting the evaluation of the CT scans, all choices were carefully discussed by the observers. Observers also made a pilot of 5 CT scans in order to make sure that all observers understood how to fill in the forms. The Radiologist did not respond to the questions: "Need for septoplasty" and "Grade of surgeon's confidence based on images".

\section{Questionnaire}

During the same day of performing sinus CT scans, the subjects were asked to fill in a questionnaire in order to get the patient history data. The questions concerned about the patient's medical history such as the presence of physician-diagnosed allergic rhinitis, asthma, previous nasal polyps and smoking habits (Table 1). We also asked duration of CRS symptoms, number of antibiotic courses for acute rhinosinusitis, the use of intranasal corticosteroids, and the use of per oral corticosteroids for CRS during the last 12 months; and the number of previous sinonasal operations (Table 1). The current sinonasal symptoms were asked by a Visual Analog Scale (VAS) score (Table 1). 


\section{Data analysis}

Statistical analysis was carried out by the SPSS Base 15.0 Statistical Software Package (SPSS Inc.,

Chicago, IL, USA). Cohen's kappa was used to compare the degree of inter-observer agreement of CT scans. The calculation is based on the difference between how much agreement is actually present compared to how much agreement would be expected to be present by chance alone. The established interpretation of Kappa-value is classified into 6 subgroups: Poor $<0.2$, Fair 0.21-0.4, Moderate 0.41-0.6, Good 0.61-0.8, and Very Good 0.81-1.0. A value under zero means that the agreement is worse than by chance, and the value range is from -1 to +1 [15]. Associations were assessed by the Fisher's exact test. Two-tailed P-values of $<0.05$ were considered statistically significant.

\section{Results}

\section{Patient characteristics}

Patient characteristics are given in Table 1. The age of the subjects varied from 13 to 77 years, with the average of 43 years by the time of taking the CT scans (Table 1). 23 (40\%) of the patients were men. $29(51 \%)$ of the whole group had allergic rhinitis, $13(23 \%)$ had diagnosed asthma and 13 (23\%) had nasal polyps (Table 1). 35 out of 57 patients ended up having sinonasal surgery during the following 12 months after they had undergone sinus CT scans (Table 1). The regularly used medications excluding those for CRS or related diseases were for heart and vascular diseases (10 patients), hypothyreosis (5 patients), migraine (3 patients), hyper-cholesterolemia (2 patients), gastroesophageal reflux disease (2 patients), cystitis (1 patient), irritable bowel syndrome (1 patient), melanoma (1 patient), otosclerosis ( 1 patient), prostate hypertrophy ( 1 patient) and rheumatoid arthritis (1 patient). 
The median (min-max) duration of CRS symptoms was 8.3 (0-54 years) prior to taking the CT scan (Table 1). The median (min-max) number of antibiotic courses for acute rhinosinusitis during the past two years was $4.8(0-15)$ (Table 1$)$. The median VAS scores of sinonasal symptoms were between 3.5-5.8 (Table 1). $46(81 \%)$ of the patients had current use of intranasal corticosteroids. None of the patients reported as having used peroral corticosteroids during the past 12 months (Table 1). $12(21 \%)$ of the patients had undergone a previous sinus operation such as inferior or middle meatal antrostomy and/or ethmoidectomy (Table 1). The median (Q1-Q3) total Lund-MacKay score was 3 (1-5) on both sides (Table 2).

\section{Inter-observer agreement}

In general, there was moderate to good inter-observer agreement of the structures. When evaluating the agreement between radiologist and ENT resident, the inter-observer agreement was moderate (kappa 0.4-0.6) in the majority of structures. The greatest agreement was detected in the size of anterior and posterior ethmoid sinus (kappa 1.000 each side) and frontal recess (kappa 0.888 right side and 0.802 left side) (Tables 3-4). The greatest disagreements were found in anterior ethmoidal artery (kappa 0.193 right side and 0.197 left side), the quality of nasal mucosa (normal-polypous) (kappa -0.046 right side and -0.044 left side), and the thickness of nasal mucosa (kappa -0.069 right side and -0.056 left side) (Tables 3-4).

When evaluating the agreement between radiologist and ENT surgeon, the inter-observer agreement was fair (kappa 0.2-0.4) in the majority of structures. The greatest agreement was achieved when radiologist and ENT surgeon evaluated signs of previous sinus surgery (kappa 0.895 right side and 0.843 left side), and Lund-Mackay score of the ostiomeatal unit (kappa 0.877 right side and 0.781 left side) (Table 3). The greatest disagreements were in septum turbinate (kappa -0.061 right side and -0.033 left side) and orbital lamina of ethmoidal bone (thickness) (kappa -0.016 each side) (Table $3)$. 
Overall agreement between ENT surgeon and ENT resident was fair (kappa 0.2-0.4). The greatest agreements were at previous sinus surgery performed (kappa 0.901 right side and 0.855 left side) and Lund-Mackay sinus score of frontal sinus (kappa 0.740 right side and 0.849 left side) (Table 4). The greatest disagreements were in septum turbinate (kappa -0.138 right side and 0.002 left side) and location of the anterior ethmoidal artery (kappa -0.009 each side) (Table 3).

\section{The percentage of responses 'Not detectable'}

The three observers had also the possibility to fill the choice 'not detectable' in 30/49 structures. 'Not detectable' was not an option in the items concerning LM scoring and sinus size (hypoplasia/normal/hyperplasia), Keros classification, grade of surgeon's confidence based on images, and mucosa of nasal cavity (extent of edema). The percentage of the responses 'Not detectable' varied between 0-18\% (Radiologist), 0-24\% (ENT surgeon), 0-28\% (ENT resident) (Table 5). In general, the percentages of the responses 'Not detectable' did not statistically significantly differ between radiologist, ENT surgeon or ENT resident (Table 5). After Bonferroni correction, the response-rate of 'Non detectable' was statistically significantly different between the observers in the following structures: Infraorbital cell (ENT surgeon vs. resident), Concha bullosa superior (Radiologist vs. ENT surgeon), Mucosa of pneumatized superior turbinate (Radiologist vs. ENT surgeon), and Anterior ethmoidal artery (Radiologist vs. ENT surgeon; ENT surgeon vs. resident) (Table 5).

\section{Discussion}

This study was carried out to compare inter-observer agreement in sinus CT scans. The results demonstrated that there can be considerable variation in the evaluation of sinus CT scans between observers. Generally three observers agreed for structures like "Previous sinus surgery performed", 
"Frontal recesses" and "Lund-Mackay score of posterior ethmoid sinus". Yet, there were several structures with fair to poor inter-observer reproducibility. There were a few operatively critical structures that had poor inter-observer agreement: location of anterior ethmoidal artery, optic nerve, insertion of the uncinated process, and Keros class. These vital structures and their relationship to operational areas need to be clear prior to performing advanced surgery of the sinonasal trac [16-18]. Although, severe complications occur rarely in ESS, the risk for rupture of anterior ethmoidal artery does exist in advanced sinus surgery.

To the knowledge of the authors there is little previous evidence of the level of agreement when evaluating sinus CT scans. It is known that the extent of CRS, such as polypous and severe CRS interfere the evaluation of CT scans ${ }^{1}$. Although the radiological findings of CRS were not the scope of this study, the observers reported that evaluation was more difficult if the patient had strongly polypous mucosa.

Only few previous studies exist on the inter-observer agreement of CT scans of other parts of human body. Two consultant musculoskeletal radiologists evaluated $50 \mathrm{CT}$ arthrograms of the shoulder [12]. The study group found that the level of agreement by Kappa statistic was moderate to fair in most findings (anterior capsular laxity, Hill-Sachs fracture, soft tissue Bankart), demonstrating considerable inter-observer variation [12]. The authors highlighted the potential difficulties in reporting such images and suggested ways by which the report could be more focused to provide a clinically reliable report and one that accurately matches the surgical findings [12].

Based on our analyses, the overall agreement between radiologist and ENT resident were moderate, whereas agreement was fair between radiologist and ENT surgeon as well as between ENT surgeon and ENT resident. We wanted to see if the lower agreement between radiologist and ENT surgeon and the higher agreement between radiologist and ENT resident could be explained by the fact that 
radiologist and ENT resident would have answered more often "Not detectable" for the structures than ENT surgeon. Yet, our results did not support this idea, and thus our study was not able to respond what is the reason behind inter-observer disagreement. It could be speculated that the differences reflect the fact that radiologist and ENT resident could have more analytical approach to the CT scan evaluation. ENT surgeon's view of the safe location of certain critical structures might be based more on the operative experience and clinical view than what can be detected from the CT scans. Yet further studies to prove this are needed.

It seems that there are different ways to evaluate CT scans, and the only right one cannot be fully determined. This also indicates the importance of discussion in radiologic meetings, not only relying on the radiologist's written response of the CT scans. Taken together our findings would indicate the importance of training CT scan observing for residents in radiology and otorhinolaryngology. The findings also suggest that consultations might be equally important for experienced otorhinolaryngologists in some cases.

The limitations of the study are that we did not use modern low dose CT machinery (such as cone beam CT). The results of cone beam CT might be relatively comparable to these results of traditional CT, as cone beam CT has shown detect sinonasal structures similarly [19]. Yet, this needs to be proven by further studies.

\section{Conclusion}

Our study demonstrated considerable inter-observer variation in a few surgically important structures. This could indicate the significance for consultation when evaluating sinus CT scans of CRS patients for operative planning. 


\section{Acknowledgements}

The authors thank MD Mikko Suvinen and MD Anna-Maija Kuukka for collaboration and research nurse Marja-Leena Oksanen for her excellent assistance. The study was supported in part by research grants from the Ahokas Foundation, Competitive Research Funding of the Tampere University Hospital (Grants 9H067, 9J108, 9L087), the Finnish Medical Society Duodecim, the Finnish Society of Allergology and Immunology, Helsinki University Central Hospital Research Funds, the Ida Monti Foundation, the Jane and Aatos Erkko Foundation, the Väinö and Laina Kivi Foundation, and the Yrjö Jahnsson Foundation. The authors thank University of Helsinki.

\section{Author contributions}

S T-S and JN provided the study plan (with MR and PD), made the applications, recruited the subjects, and evaluated the CT scans (with AM). AJ, ET, MK, HH, JM, and ST-S performed the data management and wrote the manuscript. All authors reviewed critically the manuscript.

\section{References}

[1] Fokkens WJ, Lund VJ, Mullol J, et al. European position paper on rhinosinusitis and nasal polyps 2012. Rhinology 2012;50:1-298. 
[2] Holbrook EH, Brown CL, Lyden ER, Leopold DA. Lack of significant correlation between rhinosinusitis symptoms and specific regions of sinus computer tomography scans. American Journal of Rhinology 2005;19(4):382-387.

[3] Hopkins C, Browne JP, Slack R, Lund V, Brown P. The Lund-Mackay staging system for chronic rhinosinusitis: how is it used and what does it predict? Otolaryngology Head and Neck Surgery 2007;137(4):555-561.

[4] Lund VJ, Kennedy DW. Stagning for rhinosinusitis. Otolaryngology - Head and Neck Surgery 1997;117(3):35-40.

[5] Ding J, Sun G, Lu Y, et al. Evaluation of anterior ethmoidal artery by 320-slice CT angiography with comparison to three-dimensional spin digital subtraction angiography: initial experiences. Korean Journal of Radiology 2012;13(6):667-673.

[6] Bradley DT, Kountakis SE. The role of agger nasi air cells in patients requiring revision endoscopic frontal sinus surgery. Otolaryngology - Head \& Neck Surgery 2004;131(4):525-527.

[7] Choby GW, Hobson CE, Lee S, Wang EW. Clinical effects of middle turbinate resection after endoscopic sinus surgery: a systematic review. American Journal of Rhinology \& Allergy 2014;28(6):502-507.

[8] Panou A, Stanitski DF, Stanitski C, Peccati A, Portinaro NM. Intra-observer and inter-observer errors in CT measurement of torsional profiles of lower limbs: a retrospective comparative study. Journal of Orthopaedic Surgery 2015;10(1):67.

[9] Ramakrishnan VR, Suh JD, Kennedy DW. Ethmoid skull-base height: a clinically relevant method of evaluation. International Forum of Allergy \& Rhinology 2011;1(5):396-400. 
[10] Solanki J, Gupta S, Patil N, Kulkarni VV, Singh M, Laller S. Prevelance of Haller's Cells: A Panoramic Radiographic Study. Journal of Clinical and Diagnostic Research 2014;8(9):R01-4.

[11] Albrecht MH, Wichmann JL, Muller C, et al. Assessment of colorectal liver metastases using MRI and CT: impact of observer experience on diagnostic performance and inter-observer reproducibility with histopathological correlation. European Journal of Radiology 2014;83(10):17521758.

[12] Fogerty S, King DG, Groves C, Scally A, Chandramohan M. Interobserver variation in reporting CT arthrograms of the shoulder. European Journal of Radiology 2011;80(3):811-813.

[13] Khojastepour L, Mirhadi S, Mesbahi SA. Anatomical Variations of Ostiomeatal Complex in CBCT of Patients Seeking Rhinoplasty. Journal of Dentistry 2015;16(1):42-48.

[14] Vogiatzi T, Kloukos D, Scarfe WC, Bornstein MM. Incidence of anatomical variations and disease of the maxillary sinuses as identified by cone beam computed tomography: a systematic review. The International Journal of Oral \& Maxillofacial Implants 2014;29(6):1301-1314.

[15] Viera AJ, Garrett JM. Understanding interobserver agreement: the kappa statistic. Family Medicine 2005;37(5):360-363.

[16] Stammberger H. Endoscopic endonasal surgery--concepts in treatment of recurring rhinosinusitis. Part I. Anatomic and pathophysiologic considerations. Otolaryngology - Head \& Neck Surgery 1986;94(2):143-147.

[17] Zinreich SJ, Kennedy DW, Rosenbaum AE, Gayler BW, Kumar AJ, Stammberger H. Paranasal sinuses: CT imaging requirements for endoscopic surgery. Radiology 1987;163(3):769-775.

[18] Braun H, Stammberger H. The Graz' sinus-CT checklist. 2013. 
[19] Abul-Kasim K, Strombeck A, Sahlstrand-Johnson P. Low-dose computed tomography of the paranasal sinuses: radiation doses and reliability analysis. American Journal of Otolaryngology 2011;32(1):47-51. 
Table 1. Demographic factors of the subjects

\begin{tabular}{|c|c|c|}
\hline & $\mathrm{n}$ & $\%$ \\
\hline & $=57$ & \\
\hline Male gender & 23 & 40 \\
\hline Age, mean $(\min -\max )$ & $43(13-77)$ & \\
\hline \multicolumn{3}{|l|}{ Smoking } \\
\hline No & 34 & 60 \\
\hline Ex & 11 & 19 \\
\hline Yes & 12 & 21 \\
\hline Allergic rhinitis & 29 & 51 \\
\hline Asthma & 13 & 23 \\
\hline Nasal polyps & 13 & 23 \\
\hline Use of intranasal corticosteroids & 46 & 81 \\
\hline Use of peroral corticosteroids ${ }^{1}$ & 0 & 0 \\
\hline \multicolumn{3}{|l|}{ Previous operation } \\
\hline 0 & 45 & 79 \\
\hline 1 & 4 & 7 \\
\hline $2-3$ & 5 & 9 \\
\hline$\geq 4$ & 3 & 5 \\
\hline Radiological signs of previous sinus operation & 12 & 21 \\
\hline \multicolumn{3}{|l|}{ Sinus surgery and/or polypectomy performed } \\
\hline after sinus CT scans & 35 & 61 \\
\hline Duration of symptoms (years), mean (min - max) & $8.3(0-54)$ & \\
\hline \multicolumn{3}{|l|}{ Antibiotic use during the past two years } \\
\hline $\operatorname{mean}(\min -\max )$ & $4.8(0-15)$ & \\
\hline \multicolumn{3}{|l|}{ Symptoms (VAS), mean (min - max) } \\
\hline Sense of smell & $3.5(0-10)$ & \\
\hline Post-nasal drip & $5.4(0-10)$ & \\
\hline Obstruction & $5.8(0.2-10)$ & \\
\hline Facial pain & $5.3(0.3-10)$ & \\
\hline
\end{tabular}

${ }^{1}$ At least one per oral corticosteroid treatment during the last 12 months. 
Table 2. Medians and interquartile ranges (Q1-Q3) of the radiologic Lund McKay (LM) scores of the subjects

\begin{tabular}{lccccc}
\hline & \multicolumn{2}{c}{ Right } & & \multicolumn{2}{c}{ Left } \\
\cline { 2 - 3 } \cline { 5 - 5 } & Median & $\mathrm{Q}_{1}-\mathrm{Q}_{3}$ & & Median & $\mathrm{Q}_{1}-\mathrm{Q}_{3}$ \\
\hline LM score & 0 & $0-1$ & & 0 & $0-1$ \\
$\quad$ Frontal sinus & 1 & $0-1$ & & 0 & $0-1$ \\
Anterior ethmoidal sinus & 0 & $0-2$ & & 0 & $0-2$ \\
Ostiomeatal unit & 1 & $0-1$ & & 1 & $0-1$ \\
Posterior ethmoidal sinus & 0 & $0-1$ & & 0 & $0-1$ \\
Sphenoid sinus & 1 & $0.5-1$ & & 1 & $0.5-1$ \\
Maxillary sinus & 3 & $1-5$ & 3 & $1-5$ \\
LM score Total & & & & \\
\hline
\end{tabular}


Table 3. Inter-observer agreement of 49 sinonasal structures evaluated from sinus computed tomography scans

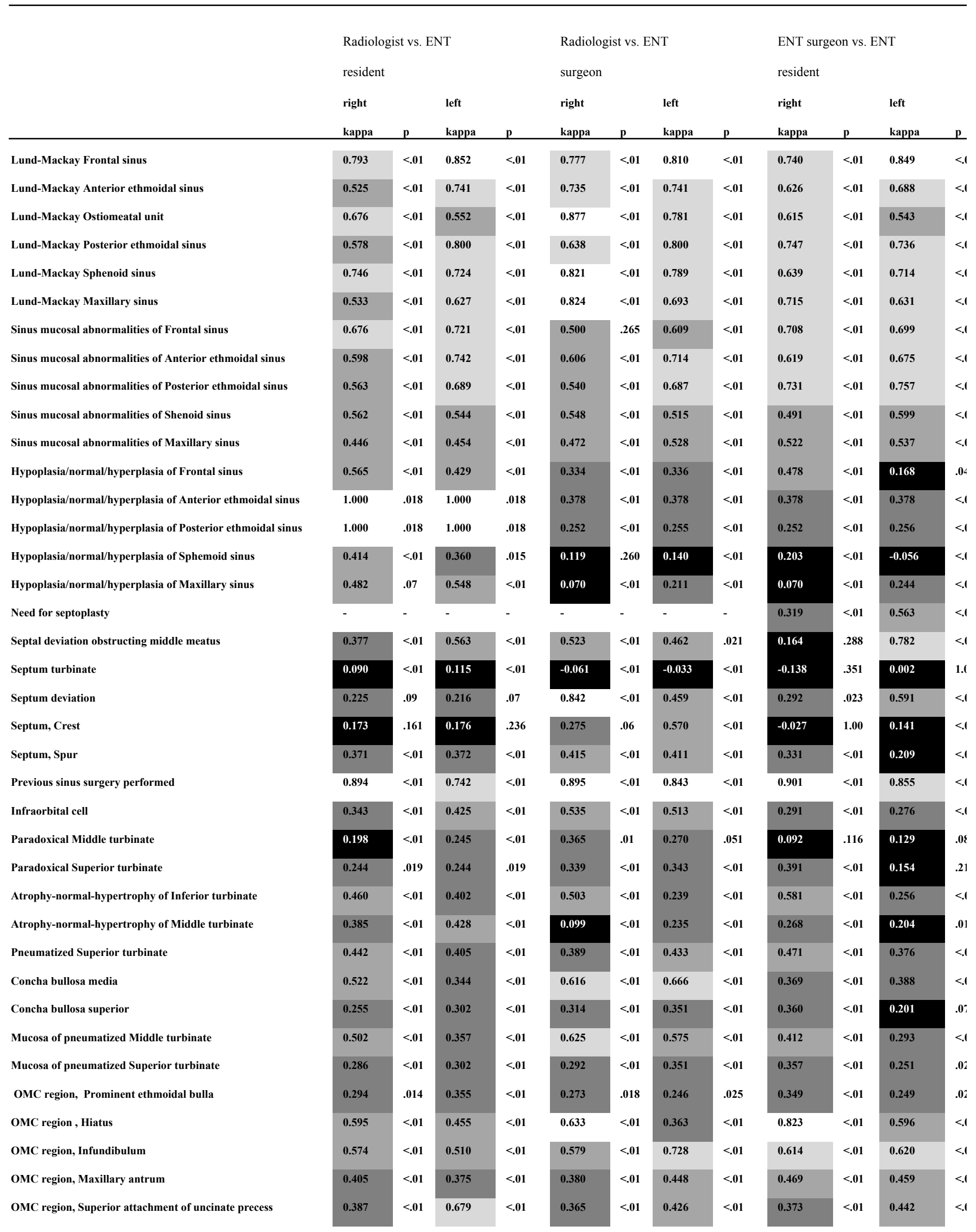




\begin{tabular}{|c|c|c|c|c|c|c|c|c|c|c|c|c|}
\hline OMC region, Acessory maxillary sinus ostium & 0.523 & $<.01$ & 0.688 & $<.01$ & 0.342 & $<.01$ & 0.591 & $<.01$ & 0.424 & $<.01$ & 0.458 & $<.1$ \\
\hline OMC region, Pneumatized superior attachment of uncin. proc. & 0.574 & $<.01$ & 0.520 & $<.01$ & 0.668 & $<.01$ & 0.702 & $<.01$ & 0.580 & $<.01$ & 0.578 & $<.1$ \\
\hline Frontal recess & 0.888 & $<.01$ & 0.802 & $<.01$ & 0.772 & $<.01$ & 0.712 & $<.01$ & 0.734 & $<.01$ & 0.750 & $<.1$ \\
\hline Sphenoethmoidal recess & 0.544 & $<.01$ & 0.431 & $<.01$ & 0.656 & $<.01$ & 0.458 & $<.01$ & 0.656 & $<.01$ & 0.584 & $<.1$ \\
\hline Anterior ethmoidal artery & 0.193 & .064 & 0.197 & .046 & 0.179 & $<.01$ & 0.203 & $<.01$ & -0.09 & $<.01$ & -0.09 & $<.1$ \\
\hline Optic nerve & 0.659 & .036 & 0.486 & .05 & -0.031 & 1 & 0.176 & .236 & 0.248 & .169 & 0.177 & .22 \\
\hline Thickness of orbital lamina of ethmoidal bone & 0.197 & .143 & 0.226 & .125 & -0.016 & 1 & -0.016 & 1 & 0.661 & $<.01$ & 0.661 & $<.1$ \\
\hline Contact to middle turbinate of orbital lamina ethmoidal bone & 0.658 & .036 & -0.009 & 1 & -0.009 & 1 & -0.009 & 1 & 0.661 & $<.01$ & 0.486 & .02 \\
\hline Keros classification & -0.045 & 68 & -0.018 & 1 & 0.344 & $<.01$ & 0.252 & $<.01$ & 0.265 & $<.01$ & 0.234 & $<.1$ \\
\hline Grade of surgeon's confidence based on images & - & - & - & - & - & - & - & - & 0.329 & $<.01$ & 0.329 & $<.1$ \\
\hline Mucosa of nasal cavity (extent of edema) & -0.075 & $<.01$ & -0.056 & $<.01$ & 0.161 & $<.01$ & 0.146 & $<.01$ & 0.328 & $<.01$ & 0.158 & .16 \\
\hline Mucosa of nasal cavity (normal-polypous) & -0.046 & .73 & -0.044 & $<.01$ & 0.097 & .267 & 0.149 & $<.01$ & 0.338 & $<.01$ & 0.235 & .01 \\
\hline
\end{tabular}

\begin{tabular}{l|l} 
Agreement & kappa \\
\cline { 2 - 2 } poor & $<.2$ \\
fair & $.21-.4$ \\
moderate & $.41-.6$ \\
good & $.61-.8$ \\
very good & $.81-1.0$
\end{tabular}

The order of the structures is the same as they were in the evaluation form. P-values by kappa-test. $\mathrm{ENT}=$ Ear nose throat; $\mathrm{OMC}=$ Ostiomeatal complex, uncin. $=$ Uncinated; proc.$=$ process.

- = The Radiologist did not respond to the questions: "Need for septoplasty" and "Grade of surgeon's confidence based on images". 
Table 4. The alphabetical order of the structures and the level of inter-observer agreement

\begin{tabular}{|c|c|c|c|}
\hline Poor & Fair & Moderate & Good * \\
\hline Anterior ethmoidal artery & $\begin{array}{l}\text { Atrophy-normal-hypertrophy of } \\
\text { Inferior turbinate }\end{array}$ & $\begin{array}{l}\text { Lund-Mackay Anterior ethmoid sinus } \\
\text { Lund-Mackay Maxillary sinus }\end{array}$ & $\begin{array}{l}\text { Frontal Recess } \\
\text { Lund-Mackay Frontal sinus }\end{array}$ \\
\hline $\begin{array}{l}\text { Atrophy-normal-hypertrophy of } \\
\text { Middle turbinate }\end{array}$ & Concha bullosa media & $\begin{array}{l}\text { Lund-Mackay Ostiomeatal unit } \\
\text { Lund-Mackay Posterior ethmoid sinus }\end{array}$ & $\begin{array}{l}\text { Lund-Mackay Sphenoid sinus } \\
\text { Previous sinus surgery performed }\end{array}$ \\
\hline Concha bullosa superior & $\begin{array}{l}\text { Grade of surgeon's confidence based } \\
\text { on images }\end{array}$ & $\begin{array}{l}\text { OMC region, Pneumatized } \\
\text { superior attachment of }\end{array}$ & \\
\hline $\begin{array}{l}\text { Contact to middle turbinate of } \\
\text { orbital lamina ethmoidal bone }\end{array}$ & Infraorbital cell & uncinate process & \\
\hline Hypoplasia/normal/hyperplasia of & $\begin{array}{l}\text { Hypoplasia/normal/hyperplasia of } \\
\text { Anterior ethmoid sinus }\end{array}$ & $\begin{array}{l}\text { Sinus mucosal abnormalities } \\
\text { of Anterior ethmoid sinus }\end{array}$ & \\
\hline Frontal sinus & Hypoplasia/normal/hyperplasia of & Sinus mucosal abnormalities & \\
\hline $\begin{array}{l}\text { Hypoplasia/normal/hyperplasia of } \\
\text { Maxillary sinus }\end{array}$ & Posterior ethmoida sinus & of Frontal sinus & \\
\hline Hypoplasia/normal/hyperplasia of & $\begin{array}{l}\text { Mucosa of pneumatized } \\
\text { Middle turbinate }\end{array}$ & $\begin{array}{l}\text { Sinus mucosal abnormalities } \\
\text { of Maxillary sinus }\end{array}$ & \\
\hline Sphemoidal sinus & & & \\
\hline & Mucosa of pneumatized & Sinus mucosal abnormalities & \\
\hline Keros classification & Superior turbinate & of Posterior ethmoid sinus & \\
\hline $\begin{array}{l}\text { Mucosa of nasal cavity } \\
\text { (extent of edema) }\end{array}$ & $\begin{array}{l}\text { Ostiomeatal complex (OMC) region, } \\
\text { Acessory maxillary Sinus ostium }\end{array}$ & $\begin{array}{l}\text { Sinus mucosal abnormalities } \\
\text { of Shenoid sinus }\end{array}$ & \\
\hline & OMC region, Hiatus & & \\
\hline $\begin{array}{l}\text { Mucosa of nasal cavity } \\
\text { (normal-polypous) }\end{array}$ & $\begin{array}{l}\text { OMC region, Infundibulum } \\
\text { OMC region, Maxillary antrum }\end{array}$ & Sphenoethmoidal recess & \\
\hline Optic nerve & $\begin{array}{l}\text { OMC region, Superior attachment } \\
\text { of uncinate precess }\end{array}$ & & \\
\hline Paradoxical Middle turbinate & OMC region, Prominent ethmoid bulla & & \\
\hline Paradoxical Superior turbinate & $\begin{array}{l}\text { Pneumatized Superior turbinate } \\
\text { Septum deviation }\end{array}$ & & \\
\hline $\begin{array}{l}\text { Septal deviation obstructing } \\
\text { middle meatus }\end{array}$ & & & \\
\hline Septum Crest & & & \\
\hline Septum Spur & & & \\
\hline
\end{tabular}


The agreement level is determined by the lowest kappa values detected in the inter-observer comparisons of the structure per each side. ${ }^{*}$ No "very good" agreements were detected. 
Table 5. The percentage of the responses 'not detectable'

\begin{tabular}{|c|c|c|c|c|c|c|}
\hline & Radiologist & $\begin{array}{c}\text { ENT } \\
\text { surgeon }\end{array}$ & $\begin{array}{c}\text { ENT } \\
\text { resident }\end{array}$ & $\mathrm{p}^{1}$ & $p^{2}$ & $p^{3}$ \\
\hline & $\%$ & $\%$ & $\%$ & & & \\
\hline Lund-Mackay Frontal sinus & - & - & - & - & - & - \\
\hline Lund-Mackay Anterior ethmoidal sinus & - & - & - & - & - & - \\
\hline Lund-Mackay Ostiomeatal unit & - & - & - & - & - & - \\
\hline Lund-Mackay Posterior ethmoidal sinus & - & - & - & - & - & - \\
\hline Lund-Mackay Sphenoid sinus & - & - & - & - & - & - \\
\hline Lund-Mackay Maxillary sinus & - & - & - & - & - & - \\
\hline Sinus mucosal abnormalities of Frontal sinus & - & - & - & - & - & - \\
\hline Sinus mucosal abnormalities of Anterior ethmoidal sinus & $\cdot$ & - & $\cdot$ & - & - & - \\
\hline Sinus mucosal abnormalities of Posterior ethmoidal sinus & - & - & - & - & $\cdot$ & - \\
\hline Sinus mucosal abnormalities of Shenoidal sinus & - & - & - & - & $\cdot$ & - \\
\hline Sinus mucosal abnormales of Maxillary sinus & - & - & - & - & - & - \\
\hline Hypoplasia/normal/hyperplasia of Frontal sinus & - & - & - & - & - & - \\
\hline Hypoplasia/normal/hyperplasia of Anterior ethmoidal sinus & - & - & - & - & - & - \\
\hline Hypoplasia/normal/hyperplasia of Posterior ethmoidal sinus & $\cdot$ & - & $\cdot$ & - & $\cdot$ & - \\
\hline Hypoplasia/normal/hyperplasia of Sphemoidal sinus & - & - & - & - & $\cdot$ & - \\
\hline Hypoplasia/normal/hyperplasia of Maxillary sinus & - & - & - & - & - & - \\
\hline Need for septoplastia & 0 & 0 & 0 & 1.00 & 1.00 & 1.00 \\
\hline Septal deviation obstructing middle meatus & 0 & 0 & 0 & 1.00 & 1.00 & 1.00 \\
\hline Septum turbinate & 0 & 2 & 2 & .50 & .50 & 1.00 \\
\hline Septum deviation & 0 & 0 & 0 & 1.00 & 1.00 & 1.00 \\
\hline Septum Crest & 0 & 1 & 0 & 1.00 & 1.00 & 1.00 \\
\hline Septum Spur & 0 & 2 & 0 & .50 & 1.00 & .50 \\
\hline Previous sinus surgery performed & 0 & 2 & 0 & .50 & 1.00 & .50 \\
\hline Infraorbital cell & 4 & 0 & 11 & .06 & .041 & $<.001$ \\
\hline Paradoxical Middle turbinate & 5 & 3 & 8 & .50 & .60 & .14 \\
\hline Paradoxical Superior turbinate & 9 & 21 & 19 & .015 & .035 & .87 \\
\hline Atrophy-normal-hypertrophy of Inferior turbinate & 4 & 2 & 2 & .68 & .68 & 1.00 \\
\hline Atrophy-normal-hypertrophy of Middle turbinate & 8 & 4 & 8 & .25 & 1.00 & .25 \\
\hline Pneumatized Superior turbinate & 18 & 23 & 18 & .41 & 1.00 & .51 \\
\hline Concha bullosa media & 5 & 4 & 11 & .75 & .22 & .07 \\
\hline Concha bullosa superior & 9 & 23 & 28 & .006 & $<.001$ & .447 \\
\hline Mucosa of pneumatized Middle turbinate & 5 & 4 & 11 & .75 & .22 & .07 \\
\hline Mucosa of pneumatized Superior turbinate & 9 & 24 & 28 & .004 & $<.001$ & .55 \\
\hline OMC region, Prominent ethmoidal bulla & 4 & 6 & 7 & .54 & .38 & 1.00 \\
\hline OMC region, Hiatus & 5 & 0 & 0 & .029 & .029 & 1.00 \\
\hline OMC region, Infundibulum & 3 & 0 & 0 & .25 & .25 & 1.00 \\
\hline OMC region, Maxillary antrum & 4 & 0 & 0 & .06 & .06 & 1.00 \\
\hline OMC region, Superior attachment of uncinate precess & 14 & 11 & 7 & .55 & .13 & .48 \\
\hline OMC region, Acessory maxillary sinus ostium & 11 & 2 & 11 & .01 & 1.00 & .006 \\
\hline OMC region, Pneumatized superior attachment of uncin. proc. & 11 & 9 & 7 & .82 & .48 & .81 \\
\hline Frontal recess & 0 & 0 & 0 & 1.00 & 1.00 & 1.00 \\
\hline
\end{tabular}


Sphenoethmoidal recess

Anterior ethmoidal artery

Optic nerve

Thickness of orbital lamina of ethmoidal bone

Contact to middle turbinate of orbital lamina ethmoidal bone

Keros classification

Grade of surgeon's confidence based on images

Mucosa of nasal cavity (extent of edema)

Mucosa of nasal cavity (normal-polypous)

3
12
0
0
0
-
-
-

0

3
0
0
0
-
-
-

0

0

2

0

2

4

11

0

0

1

1

.

0

$\begin{array}{rrr}.25 & 1.00 & .06 \\ <.001 & .84 & <.001 \\ 1.00 & 1.00 & 1.00 \\ .50 & 1.00 & .50 \\ .50 & 1.00 & 1.00 \\ - & - & - \\ - & - & - \\ - & - & - \\ 1.00 & 1.00 & 1.00\end{array}$

The $p$-values by Fisher's exact test; $\mathrm{p}^{1}=$ Radiologist vs. Ear nose throat $($ ENT $)$ surgeon; $\mathrm{p}^{2}=$ radiologist vs. ENT resident; $\mathrm{p}^{3}=$ ENT surgeon vs. ENT resident. OMC $=$ Ostiomeatal complex, uncin. $=$ Uncinated; proc.$=$ process. 